\title{
LAS QVERIMONIAE: RECLAMACIONES ADMINISTRATIVAS DURANTE LA DINASTÍA CONSTANTINIANA*
}

\section{THE QVERIMONIAE: ADMINISTRATIVE COMPLAINTS UNDER THE CONSTANTINIAN DYNASTY}

\author{
Esteban Moreno Resano \\ Universidad de Zaragoza \\ estmores@unizar.es
}

ORCID: 0000-0003-4641-5132

DOI: $10.1387 /$ veleia.18079

\begin{abstract}
Resumen: Las leyes imperiales de los siglos IV, v y vi d.C. comprendían la posibilidad de que los ciudadanos romanos pudieran presentar ante los príncipes reclamaciones administrativas (llamadas querimoniae) contra la actuación de magistrados u oficiales que hubieran obrado con negligencia o desidia en el ejercicio de sus funciones. Este estudio analiza exclusivamente los casos documentados durante la dinastía constantiniana (306-363), período durante el cual se configuró este procedimiento. Se trataba de un medio legal de control institucional introducido por Constantino a partir del año 313, con el fin de garantizar el cumplimiento de las leyes, la fidelidad del personal burocrático y la estabilidad política en una época alterada por los conflictos civiles.

Palabras clave: Querimoniae, Codex Theodosianus, Imperio romano tardío, administración.

Abstract: The imperial laws from the 4th to 6th centuries AD allowed the Roman citizens to make administrative complaints (so-called querimoniae) before the princes against neglectful or treacherous actions of magistrates or officers. This paper focuses only on the documented cases under the Constantinian dynasty (306-363), the period in which this legal procedure was created. It was a legal way of institutional control established by Constantine in 313, and it aimed at assuring the fulfillment of law, the bureaucracy's loyalty and the political stability at a time disturbed by civil conflicts.

Keywords: Querimoniae, Codex Theodosianus, Later Roman Empire, administration.
\end{abstract}

Recibido: 10-06-2016

Informado: 03-11-2016

Definitivo: 12-01-2017

* Este trabajo ha sido realizado en el marco del Proyecto de Investigación HAR2013-41470, financiado por el Ministerio de Economía y Competitividad, y del Grupo Hiberus, subvencionado por el Gobierno de Aragón. 
Las reformas institucionales del Imperio romano tardío, comenzadas por Diocleciano y continuadas por Constantino y sus sucesores, dieron lugar a una mejor organización interna, basada en la reordenación territorial, la jerarquización burocrática y la transformación del ejército ${ }^{1}$. Estos cambios respondían a fines primordialmente pragmáticos, pues, por lo general, pretendían lograr que los príncipes pudieran ejercer con mayor eficacia su poder después de las convulsiones del siglo III $^{2}$. Sin embargo, el nuevo sistema administrativo pronto reveló adolecer de graves problemas por lo que se refiere a su funcionamiento. Las distancias entre los centros de poder y los lugares donde se aplicaban las medidas legislativas y la falta de recursos económicos públicos explican en buena parte su escasa eficacia ${ }^{3}$. Pero su principal debilidad radicaba en la corrupción generalizada de los oficiales imperiales ${ }^{4}$. Al parecer, tales prácticas se habían extendido a consecuencia de la reforma de la organización provincial llevada a cabo por Diocleciano. Las causas fueron varias, aunque se pueden concretar en dos: en primer lugar, el aumento del número de provincias dificultaba el control de cada gobernador y de sus subalternos por parte de los emperadores; pero, además, muchos de los nuevos cargos administrativos eran de origen modesto, y encontraron en el ejercicio de sus funciones una forma de enriquecimiento rápido ${ }^{5}$. Ante la generalización de los malos usos, se buscaron distintos arbitrios. El primero fue la inspección, desempeñada fundamentalmente por los agentes in rebus ${ }^{6}$. Otro mecanismo de supervisión habitual fue la imposición de la obligación de informar con detalle mediante carta al emperador de determinadas gestiones llevadas a cabo por magistrados y oficiales ${ }^{7}$. Pero también se quiso tener un mayor y mejor control de la actuación de los responsables públicos ofreciendo a los ciudadanos la posibilidad de presentar al emperador quejas administrativas, llamadas en latín querimoniae ${ }^{8}$. Su uso está documentado entre los años 313 y 531, pero sólo se empleó de modo regular de 313 a 433․ En cualquier

\footnotetext{
1 Sobre los rasgos generales de las reformas administrativas romanas tardías, véase: Jones 1964, I, 366-410; Jones 1964, II, 563-606; Gaudemet 1966, 661-684; Piganiol 1972², 335-359; De Martino 1975.

2 Gaudemet 1979, 255.

3 Millar 1977, 618; Kelly 2004, 117.

4 Como «corrupción» se entiende cualquier práctica contraria a las leyes imperiales llevada a cabo por oficiales o magistrados en el ejercicio de sus funciones, por norma general, con fines lucrativos. No obstante, "corrupción» es un concepto contemporáneo difícilmente aplicable a las irregularidades administrativas en el mundo antiguo. Si bien es cierto que este tipo de prácticas estaban generalizadas (Schuller 1975; Veyne 1981; MacMullen 1988; Delmaire 1995, 175-176), algunos autores han destacado que determinados emperadores (en particular, Diocleciano, Constantino, Juliano y Valentiniano I) pusieron gran empeño en erradicarlas (Cecconi 2005, 303; Marcone 2006, 117-119, 125126).

5 Slootjes 2003, 324-325. Véase también al respecto: Slootjes 2006.

6 Remito acerca de esta corporación a la monografía de Di Salvo, cf. Di Salvo 2005.

7 Cuestión analizada en Moreno Resano 2015.

8 Es esta una cuestión apenas tratada en la investigación moderna, salvadas las breves indicaciones que hizo
}

Heumann de esta figura jurídica. Cf. Heumann, Seckel 1907, 94, 486.

${ }^{9}$ Hay dieciséis referencias a las querimoniae en la legislación del período constantiniano (306-361), cinco en las normas de época valentiniana (364-379) y catorce en los textos teodosianos (379-455), que son: CTh. X, 4, 1 (Br. X, 3, 1) -313-; CTh. XI, 30, 9 (=CI. VII, 62, 15) -319-; CI. II, 20, 8 (319); CTh. XI, 30, 11 (319); CTh. XII, 1,8 (CI. I, 56, 1) y CTh. XI, 30, 12 (323); CTh. XIV, 4, 2 (324 ó 326); CTh. I, 5, 1 (325); CTh. I, 5, 2 (327); CTh. I, 6, 4 (328); CTh. I, 16, 7 (331); CTh. VIII, 15, 2 (334); CTh. XII, 1, 21 (335); CTh. XII, 1, 27 (339); CTh. VII, 9, 1 (340); CTh. XI, 34, 2 (355); CTh. II, 1, 3 (357); CTh. VIII, 4, 6 (358); CI. III, 26, 9 (365); CTh. XII, 1, 71 (370); CTh. XIII, 10, 7 (371); CTh. XIII, 9, 2 (372 ó 375); CTh. VI, 4, 22 (373); CI. I, 40, 6 (385); CTh. VI, 2, 15 (393); CTh. XIII, 11, 5 (CI. XI, 58, 5) -393-; CTh. XIII, 1, 16 (399); CTh. XI, 1, 26 (399); CTh. I, 10, 7 (CI. I, 32, 1) - 401-; CTh. XIII, 9, 6 (CI. XI, 6, 5) -412-; CTh. XI, 29, 6 (416); CTh. XIII, 11, 15 (417); CTh. XI, 30, 67 (CI. VII, 62, 31) -423-; CTh. X, 21, 3 (CI. XI, 9, 4) —424-; CTh. IV, 14, 1 (424); CTh. XII, 6, 32 (429); CI. I, 59, 9 (433); CI. I, 49, 1 (479); CI. III, 24, 3 (485); CI. XII, 19, 14 (Justino); CI. VIII, 55, 10 (530); CI. I, 4, 31; II, 41, 2; VII, 40, 2 (531). Las referencias a las querimoniae posteriores 
caso, este trabajo sólo se propone estudiar su origen, desarrollo y funcionalidad durante la dinastía constantiniana (306-363).

Una querimonia (cuya instrucción aparece designada con el verbo conqueri) era una reclamación dirigida a una instancia superior por un ciudadano o grupo de ciudadanos acerca de una decisión particular o de la actuación en general de un cargo público en el ejercicio de sus funciones (por negligencia, venalidad o prevaricación) o bien acerca de una situación creada por la aplicación de una medida legislativa u orden del emperador ${ }^{10}$. El término en cuestión significaba «lamento» o «queja» fuera del campo semántico del derecho ${ }^{11}$. No era novedoso, sin embargo, su empleo en textos legislativos, pues había aparecido ya en normas de época severiana, pero con otra acepción, designando las reclamaciones realizadas por la vía judicial de cuestiones de índole privada ${ }^{12}$. La palabra conservó uno y otro significado hasta época teodosiana, aunque sólo se empleó con su antiguo valor en tres ocasiones a lo largo de los siglos IV $\mathrm{y} \mathrm{v}^{13}$.

La primera noticia que se tiene de una queja administrativa dirigida al emperador está documentada en una ley del año 313, que había sido enviada al Vicario del Prefecto de la Ciudad de Roma, Filipo ${ }^{14}$. La disposición invitaba a los ciudadanos a denunciar mediante una querimonia los comportamientos abusivos de los procuradores de la res priuata imperial, esto es, de los administradores del patrimonio personal del emperador en cada provincia. Estas actuaciones debían de consistir, por lo que dice el texto, en reclamaciones fraudulentas y exigencias ilícitas. De comprobarse las acusaciones, el culpable sería condenado a la hoguera ${ }^{15}$. Los dispositivos, expresados en estilo impersonal, no especifican los procedimientos a seguir para hacer la reclamación. La glosa teodosiana, advierte, no obstante, de que la queja debía ser dirigida directamente al emperador. Esta se tenía que realizar, probablemente, siguiendo los cauces burocráticos habituales en la época, que obligaban a presentarla ante el prefecto urbano ${ }^{16}$.

Esta medida sólo se explica en el contexto inmediatamente posterior a la derrota de Majencio por Constantino en $312^{17}$. Parece estar destinada a castigar a los oficiales del patrimonio imperial que se habían estado requisando arbitrariamente propiedades a supuestos ciudadanos afectos al príncipe vencido. Al hacerse dueño de las provincias de Majencio, Constantino emplazó a sus oficiales en el lugar que habían ocupado los de su cuñado para poner al frente de la administración a personas que le fueran fieles, como demuestra el caso particular de Junio Baso ${ }^{18}$. Sin embargo, esta previsión no tuvo los resultados esperados. Una ley de 315 confirma que el emperador repartió en régimen de posesión tierras requisadas entre quienes habían colaborado con él entre 313 y $315^{19}$. Pero, al mismo tiempo, se dieron casos de oficiales que no hacían efectivas las donaciones imperia-

al año 433, que aparecen en constitutiones de los emperadores Zenón, Justino y Justiniano son reducidas en número y deben de ser un intento de recuperación de un procedimiento administrativo antiguo como signo de la tendencia clasicista del derecho de finales del siglo v y comienzos del vi.

10 Millar no reconoce una diferencia explícita entre las appellationes y las querimoniae (Millar 1977, 515). No obstante, el empleo de diferentes términos permite inferir que se trataba de procedimientos distintos.

11 Forcellini 1940, 1010.

12 CI. II, 30, 1 (197); CI. IV, 30, 8 (228); CI. IV, 21, 5 (240); CI. III, 35, 3; IX, 2, 4 (241); II, 50, 7 (294).
13 CTh. II, 26, 1 (CI. III, 39, 3) -330-; CTh. II, 21, 1 (CI. III, 30, 1) -358-; CI. VI, 56, 5 (426).

14 CTh. X, 4, 1 (Br. X, 3, 1). El lugar de la data (Heraclea) no parece corresponder a la ley, ya que estaba destinada a Roma en 313, cuando Licinio tenía autoridad sobre las provincias orientales (Corcoran 2000², 292).

15 Sobre los términos de esta ley, cf. ReitzensteinRonning 2015, 277.

16 CTh. X, 4, 1, Interpretatio.

17 Véase al respecto: Van Dam 2011, 155-218.

18 Porena 2012, 301.

19 CTh. X, 1, 1: (...) meritis obsequiisque (...). Cf. Teall 1967, 21. 
les, como atestigua otra provisión de $319^{20}$. A partir de estas situaciones Constantino dedujo que debía introducir mecanismos administrativos para controlar a sus oficiales y verificar el cumplimiento de sus órdenes, entre los que se encontraba la querimonia.

La disposición tiene un innegable propósito propagandístico: Constantino se presentaba como un emperador que asumía la responsabilidad de administrar el Imperio conforme a las leyes y de mirar porque estas se cumplieran, velando así por la protección de los ciudadanos romanos frente a las falsas acusaciones y robos perpetrados por sus oficiales ${ }^{21}$. Con tal fin, el léxico empleado en la medida es conminatorio, pues advierte de que la pena sería especialmente severa porque la infracción había sido cometida por personas que servían al emperador y que, por tanto, debían acatar sus órdenes, para no menoscabar su majestad ${ }^{22}$. Por esta razón indicaba que quien se viera afectado por la mala actuación de un oficial imperial no dudara en presentar las quejas oportunas, y, de hecho, se debieron de presentar algunas en 315 y 319, según demuestran las leyes emitidas en dichos años.

Como se ha podido comprobar, la facultad de la querimonia fue introducida en el ordenamiento legal romano por Constantino con un fin muy concreto: controlar la actuación de los procuradores de la res priuata. En los años sucesivos, este recurso administrativo tuvo que ser extendido a otras situaciones, que demostraban la existencia de malas prácticas por parte de magistrados y oficiales públicos, pero también de ciudadanos. Lo muestra una instrucción dirigida en 319 por el emperador a Julio Severo, entonces vicario del Prefecto del Pretorio de Italia, para recordarle que las causas que le hubieran sido expuestas mediante correspondencia para su resolución no debían ser examinadas de nuevo por un juez, puesto que la decisión imperial era concluyente. La disposición indicaba de modo claro que, en estos casos, el litigante quedaba privado del permiso de reclamar (conqueri) ${ }^{23}$. La instrucción imperial no era novedosa, puesto que reiteraba una norma ya contemplada en las Sententiae Pauli, colección de preceptos jurisprudenciales elaborada a comienzos del siglo IV a partir de textos de época severiana ${ }^{24}$. Se supone, por consiguiente, que, con el pretexto de dirigir una protesta administrativa al emperador, se había tratado de revisar el resultado de una apelación judicial, la cual, por principio jurídico, daba por finalizado un litigio. Por otra parte, evidencia de que no sólo los miembros de la burocracia perpetraban abusos, es que, el mismo año de 319, Constantino estableció un plazo máximo de dos años para formular una reclamación a propósito de perjuicios provocados por oficiales públicos, a partir de la fecha de la comisión de los hechos, y no del momento de su denuncia ${ }^{25}$.

En efecto, otra instrucción de Constantino, dirigida en 321 al Prefecto de Roma Máximo, recordaba que los ciudadanos romanos tenían el derecho de apelar una resolución judicial, siendo el prefecto responsable de recibir la petición, de guardar registro de su instrucción y de remitirla al príncipe. No obstante, la resolución de la causa que este hiciera de la causa sería conclusiva, en tanto que cerraba la posibilidad de que se formulara una querimonia o supplicatio ${ }^{26}$. El origen de esta provisión parece estar en que Máximo había rechazado varias apelaciones de sentencias judiciales $^{27}$. En principio, cuando esto sucedía, el afectado podía elevar una súplica al emperador, tal y

20 CTh. X, 1, 2.

21 Hayashi 1996, 76.

22 Desde época constantiniana, la ley del emperador será considerada inviolable, como se ha estudiado en: Moreno Resano 2014.

23 CTh. XI, 30, 9 (CI. VII, 62, 15). Sobre los términos de esta provisión, véase: Pergami 2007, 20; Dillon 2012, 243-244; Laquerriére-Lacroix 2014.
24 PS. V, 5, 1. Sobre las Pauli sententiae, cf. Liebs 1995 y 1996.

25 CI. II, 20, 8.

26 CTh. XI, 30, 11 pr. Sobre los términos de esta ley, cf. Millar 1977, 515; Gaudemet 1981, 64-66.

27 CTh. XI, 30, 11, 1: (...) ex eo querimoniae litigantium oriuntur, quod a uobis (...) appellationum adminicula respuuntur. En previsión de que se dieran estas 
como estipulaba una provisión de $316^{28}$. Según esta constitución, para dirigir una supplicatio, era preciso que al ciudadano se le hubiera denegado el derecho de apelación o que no hubiera recibido contestación ${ }^{29}$. De acuerdo con la ley de 321, la querimonia y la supplicatio eran procedimientos distintos, pues cada uno tenía su denominación. Las querimoniae, sin embargo, se empleaban en otras circunstancias. Se ha de suponer, por tanto, que la querimonia no se realizaba para obtener la resolución de una causa, sino para formalizar quejas por el comportamiento improcedente del magistrado responsable, y más, si reincidía en el mismo.

Así pues, la querimonia servía para poner de manifiesto ante el emperador casos de desamparo de los ciudadanos ante las actuaciones de los cargos públicos. El gesto del prefecto es calificado de intolerable e indigno. Por tanto, en este caso, la carta imperial adopta el tono de un serio reproche al prefecto. La respuesta que había recibido Máximo refleja bastante bien la forma de administrar el poder por parte del emperador: requería ser informado por magistrados y oficiales en caso de duda acerca de cualquier particular, antes que recibir quejas de ciudadanos ${ }^{30}$. La explicación se encuentra en el hecho de que recibir una queja reflejaba la existencia de malestar hacia la novedosa burocratización del Imperio, de modo que cualquier protesta debía ser manejada con cautela y resuelta del modo más eficaz posible. Las circunstancias políticas lo exigían, pues las relaciones con Licinio habían entrado en una grave crisis, que acabó desembocando en la segunda y última guerra civil entre los dos Augustos del Imperio en $324^{31}$.

La querimonia, sin llegar a ser definida en ningún momento como "queja administrativa», fue adquiriendo paulatinamente este significado, al menos, por lo que se refiere a su uso práctico. En este sentido, es muy revelador que una ley dirigida en 323 al gobernador de la provincia africana de Tripolitania, Florentino, concerniente a los nombramientos anuales de los decuriones que debían sufragar los gastos del annona militaris, precisara los casos en los que se podía hacer uso de la queja administrativa o delación judicial ${ }^{32}$. En esta época, la presión fiscal había transformado las magistraturas públicas, que antaño eran un honos, en una carga obligatoria. Contra el nombramiento para el ejercicio de una magistratura, Constantino advierte al gobernador de que a los decuriones no les correspondía interponer una apelación (sujeta, por lo demás, a una serie de plazos que debían ser rigurosamente cumplidos), sino una querimonia, mucho más expeditiva, y que, además, evitaba tener que abrir un proceso judicial, lento y $\operatorname{costoso}^{33}$. En este sentido, la ley obligaba a que los nombramientos para los cargos públicos se hicieran con un mínimo de tres meses de antelación antes del comienzo del ejercicio, para que los disconformes pudieran acogerse a su derecho a reclamar $^{34}$. Se deduce, por consiguiente, que una queja administrativa se resolvía de modo expeditivo dentro del plazo máximo de tres meses.

situaciones, un edicto de 325 (CTh. I, 5, 1), obligaba a los prefectos del pretorio a comunicar de oficio al emperador los casos de apelaciones desatendidas por los gobernadores provinciales, ya fuera por prevaricación o negligencia, con el fin explícito de castigarlos. Se ha de tener presente que, en virtud de una provisión de 315 (CTh. XI, 30, 3), Constantino había facultado a los gobernadores para resolver las apelaciones con funciones vicariales (cf. Millar 1977, 515). Esta circunstancia agravaba considerablemente la responsabilidad de los gobernadores en las referidas situaciones, porque, al actuar uice principis, violentaban la confianza que el emperador depositaba en ellos y comprometían su autoridad.
28 CTh. XI, 30, 6.

29 Gaudemet 1981, 69.

30 Moreno Resano 2015.

31 Maraval 2011, 135-158.

32 Este texto también presenta una anomalía en la data, pues fue consignado como lugar de recepción la ciudad de Constantinopla, antes de que Bizancio recibiera este nombre (Corcoran 2000², 286).

33 CTh. XI, 30, 12. Según Gaudemet, esta medida trataba de evitar dilaciones en la instrucción de las querimoniae. Cf. Gaudemet 1951, 67.

34 CTh. XII, 1, 8 (CI. I, 56, 1). 
La querimonia aparece claramente definida como una queja administrativa en una ley apenas un año posterior, de 324, dirigida al vicario del Prefecto del Pretorio de Italia, Lucrio Verino ${ }^{35}$. Como prefecto del pretorio, era el máximo responsable de la administración y la impartición de la justicia en la diócesis de Italia. De nuevo, Constantino se mostraba interesado en evitar las protestas, en este caso, económicas, y más en plena guerra contra Licinio. El asunto que dio origen a la instrucción imperial hace referencia a una reclamación que le habían enviado los porqueros, porque los comerciantes de los cerdos tasaban los animales por debajo de su valor, arguyendo que en otras zonas los adquirían por menos. Para evitarlo, el emperador indicó a Verino que cada año debía recabar información acerca del precio de los cerdos en cada región de Italia. Esta tenían que procurársela los jueces, esto es, los gobernadores de provincia. El fin de esta medida era informar debidamente a los porqueros acerca de los precios mínimos que se estaban marcando, teniendo en cuenta que estos debían ser proporcionales al valor que alcanzaran en el mercado los animales. El emperador no disimulaba su preocupación: insiste al prefecto en que los porqueros no debían tener quejas en el futuro, porque nada interesaba, y refleja hasta qué punto la organización corporativa de un grupo extenso de ciudadanos podía contribuir al éxito de una reclamación. Conviene tener presente que la medida no trataba de impedir el aumento de los precios, sino de que los criadores de cerdos obtuvieran un beneficio proporcional a los réditos que daba su venta a los intermediarios. Las asociaciones de ciertos profesionales (entre los que se encontraban también los constructores y laneros) merecieron un trato privilegiado por parte de Constantino. Esta actitud se explica en razón de la relevancia económica que adquirían las mercancías suministradas por estos colectivos, tal que su buena provisión garantizaba la estabilidad social y política del Imperio ${ }^{36}$.

La mención de la querimonia en la ley del año 323 dirigida a la provincia de Tripolitania quizás explique por qué en la siguiente década, la de 330, se enviaran al emperador dos reclamaciones administrativas procedentes de Africa Pronconsularis, concernientes ambas a la designación de decuriones para el desempeño de diversas cargas públicas. Por lo que consta en una orden enviada en 335 a Félix, Prefecto del Pretorio de África, los curiales de la provincia proconsular se habían quejado ante el emperador de que algunos de ellos, después de haber sido flamines, sacerdotes públicos o magistrados, estaban siendo obligados a asumir el cargo de praepositi mansionum ${ }^{37}$. Esta prestación resultaba especialmente gravosa, por los elevados gastos que suponía, dado que exigía mantener y atender las paradas de los correos imperiales. Libanio, en efecto, llegó a afirmar que estas exigencias arruinaban a sus responsables del servicio, pues debían tener dispuestos caballos de posta ${ }^{38}$. A este inconveniente se sumaba que su desempeño era considerado una injuria, al afectar a la dignidad que habían adquirido con sus anteriores nombramientos. Si la queja había llegado al Prefecto del Pretorio, cabe suponer que previamente había sido recibida por el procónsul y que este la había desestimado. La respuesta de Constantino, como en otras ocasiones, fue favorable a los solicitantes. Para justificar la resolución, el emperador esgrime dos razones: una jurídica y otra política. La de índole jurídica era que los afectados habían satisfecho los diversos honores y grados exigidos por el cursus honorum municipal y provincial según era la costumbre en África. La razón política era que Constantino no quería que pareciera que se sometía a un deshonor a los curiales africanos por decisión suya (nostro iudicio). El emperador quería guardar las apariencias y manifestar que no había sido responsable de lo ocurrido. Por consiguiente, las culpas quedaban deslizadas

35 CTh. XIV, 4, 2. Sobre los términos de esta provisión, véase: Corcoran $2000^{2}, 227$.

36 CTh. XIV, 8, 1; XIV, 30, 1; XIV, 4, 1. Cf. MacMullen 1976, 161-162.
37 CTh. XII, 1, 21. Sobre sus funciones, cf. Kolb 2000, 190-192.

38 Liban., Or. XVIII, 144. Cf. Di Salvo 2005, 85. 
hacia el procónsul, quien en todo caso, debería haber atendido la queja o dirigirla al emperador antes de obligar a asumir los munera.

No tardaron en manifestarse los problemas deducidos de estas situaciones. Los curiales de Cartago, capital de la provincia de África se quejaron en 339 al emperador, entonces Constantino II ${ }^{39}$. El motivo de la protesta era que algunos miembros de la curia se negaban a asumir cargos públicos en la ciudad alegando haber desempeñado dignidades que nunca habían tenido. Para evadir sus obligaciones cívicas, habían comprado insignias correspondientes a cargos municipales, hasta el punto de arruinar a sus familias. En este caso, la resolución imperial preveía privarles de sus falsos honores, obligándoles a asumir cargas curiales ${ }^{40}$. Es probable que esta nueva provisión imperial, dirigida en esta ocasión a Celsino, procónsul de África, fuera una respuesta a los abusos que cometían algunos curiales para tratar de alcanzar la exención de munera que ofrecía la orden de 335.

Para entender estas situaciones, tanto que los gobernadores obligaran a asumir cargas a quienes no debían hacerlo, como que los curiales incurrieran en fraude curricular para evitar asumir sus deberes públicos, recuerda que los procónsules africanos, al igual que, en general, todos los gobernadores de provincia, tenían un amplísimo margen de gestión, aunque sus actividades podían estar sometidas en cualquier momento a una inspección. Por lo tanto, la posibilidad de que los ciudadanos recurrieran a la queja administrativa para hacer llegar sus demandas al emperador daba lugar a que este llevara a cabo un control secuencial de la labor política de los gobernadores de provincia por medio de la prefectura del pretorio y de los testimonios de los ciudadanos sujetos a su autoridad. Cuestión aparte es poder determinar hasta qué punto estas circunstancias podían condicionar la autonomía administrativa de los gobernadores. La impresión es que, al menos, Constantino y sus hijos preferían que los gobernadores les consultaran por carta acerca de las cuestiones que podían dar lugar a reclamaciones oficiales antes de tomar cualquier decisión al respecto.

Los abusos de las autoridades públicas llegaron a ser una preocupación de primer orden para Constantino, por el malestar generalizado que ocasionaban en las provincias ${ }^{41}$. Tal fue así que, cuando se hizo con el control de Oriente en 324, después de la derrota de su cuñado Licinio, se debió de encontrar con varias reclamaciones que le habían dirigido ciudadanos de los nuevos territorios que habían pasado a estar bajo su autoridad a propósito de las conductas inapropiadas de algunos gobernadores. Las quejas hacían referencia, al parecer, a reclamaciones que habían sido enviadas a los gobernadores provinciales correspondientes sin que estos las hubieran atendido. La respuesta de Constantino se materializó en un edicto, dirigido en 325 a todos los provinciales, en el que les conminaba a denunciar a cualquier gobernador que hubiera actuado en calidad de juez, amigo o cortesano, que no hubiera obrado de modo honesto o que hubiera prevaricado, prometiéndoles incluso premiarles con cargos y bienes, siempre que las informaciones fueran veraces ${ }^{42}$. Con tal fin, había encargado justo antes por carta al entonces Prefecto del Pretorio de Oriente, Constancio, que recibiera las quejas pertinentes para luego comunicárselas directamente a él ${ }^{43}$. Constantino en persona asumía la labor de atender las reclamaciones, dilucidar si se debían a culpa o a negligencias de los gobernadores y de castigarlos en consideración de su responsabilidad. El verbo empleado en el edicto es coerceri. El emperador, por consiguiente, se disponía a hacer uso de la coercitio, la facultad de establecer disciplina, y, por consiguiente, restablecer el orden donde no lo había ${ }^{44}$. En considera-

39 Vogler 1979, 15, n. 11; 16, n. 14.

40 CTh. XII, 1, 27. Sobre el contenido de esta ley, véase: Millar 2004, 367.

41 Slootjes 2003, 323.
42 CTh. IX, 1, 4. Cf. Cf. Dupont 1973, 331; MacMullen 1976, 82; Millar 1977, 526-527; ReitzensteinRonning 2015, 269.

43 CTh. I, 5, 1. 
ción de estos términos, se advierte que el edicto tenía una evidente intencionalidad política, que se concretaba en la necesidad de apartar del poder por la vía jurídica a los gobernadores de provincia que habían servido a Licinio. La puesta en práctica de esta política la confirma Eusebio de Cesarea en la Vita Constantini. El obispo informa de que los gobernadores de Licinio se habían implicado en la aplicación de las medidas anticristianas ${ }^{45}$. A lo cual añade, más adelante, que Constantino había sustituido a los gobernadores de Licinio por otros, en su mayor parte fieles al cristianismo a partir de $325^{46}$. La noticia es cierta en parte, pues se llevó a cabo el relevo de los hombres de Licinio, pero no por razones religiosas, pues un reconocido senador politeísta, Valerio Próculo, fue nombrado consularis de Europa y Tracia durante los años 324 y $325^{47}$. No obstante, se puede plantear que el emperador tomó la decisión de apartar de sus cargos a aquellos magistrados de quienes sus provinciales hubieran presentado quejas o sobre los que hubiera recibido noticias que les señalaban como muy afines a Licinio o celosos en el hostigamiento de los cristianos.

No sólo fueron sustituidos los gobernadores provinciales a resultas de reclamaciones administrativas. Eusebio de Cesarea señala al respecto que los ciudadanos de las provincias orientales se habían quejado de las cargas fiscales de la iugatio-capitatio eran excesivas. Para ello, Constantino les concedió el nombramiento de nuevos agrimensores, que garantizaban la inmunidad a los reclamantes ${ }^{48}$. El miedo parece que era entonces el principal impedimento para hacer una querimonia. Si los partidarios de Licinio ocupaban la administración oriental en sus distintos niveles, es lógico que trataran de evitar que se tramitaran quejas que afectaban a otros licinianos.

No obstante, que los gobernadores provinciales se negaran a atender reclamaciones judiciales era un hecho bastante habitual. En 328 Constantino extendió esta misma disposición a la prefectura de las Galias, invocando de nuevo los mismos principios: el emperador se comprometía a establecer la disciplina y a castigar a los gobernadores que actuaran en contra de sus obligaciones, para lo cual exigía, en este caso, al prefecto del pretorio Máximo que le comunicara directamente sus nombres y la causa de la queja ${ }^{49}$. Ha de tenerse presente que, un año antes, en 327 , había adoptado en la misma prefectura medidas relativas a casos de prevaricación por parte de los gobernadores provinciales ${ }^{50}$. La provisión, también dirigida al prefecto del pretorio Máximo, señalaba que las disposiciones de los gobernadores que hubieran sido reclamadas por ser contrarias a la ley fueran recabadas por los prefectos del pretorio y privadas de vigor ${ }^{51}$.

La impresión que dan las leyes imperiales de época constantiniana es que la corrupción estaba extendida a todos los niveles de la administración, si bien las noticias conservadas afectan, principalmente, a la esfera de los rectorados provinciales en sus diversos niveles, y a la justicia pública, estrechamente vinculada a los gobernadores. Una ley de 334, enviada al vicario de la diócesis de Asia, declaraba nulas las ventas de tierras propiedad de ciudadanos particulares validadas por los ecónomos provinciales (los numerarii) como si fueran tierras públicas con el consentimiento y por orden de los gobernadores ${ }^{52}$. De nuevo, Constantino advierte de que facultaba a los afectados a reclamar el daño que se les había infligido, comprometiéndose a castigar a los culpables.

\footnotetext{
44 Sobre la imagen de Constantino como restaurador del orden, véase: Gaudemet 1949.

45 Euseb. Caes., VC, II, 1, 2.

46 Euseb. Caes., VC, II, 44.

47 CIL VI, 1691.

48 Euseb. Caes., VC, IV, 3. Sobre la iugatio-capitatio, véase: Aparicio Pérez 2012, 165-179.

49 CTh. I, 6, 4 (328).

50 CTh. I, 5, 2.
}

51 CTh. I, 5, 2. Esta disposición constata que en aquellas fechas se estaban formando archivos que recababan las sentencias reclamadas en cada provincia en las oficinas de las diferentes prefecturas del pretorio. Otra noticia referida a dichos fondos administrativos se encuentra en la primera constitución sirmondiana, del año 333 (CSirm I).

52 CTh. VIII, 15, 2. 
La difusión de la corrupción era tal que, en un edicto publicado en 331 en las provincias orientales, Constantino declaraba lo siguiente:

Que cesen ya de actuar las rapaces manos de los oficiales, ya lo digo: que cesen. Y si no cesan después de haber sido advertidos, serán castigados con la espada. Que no sea venal la cortina del juez, que la secretaría judicial no sea infame por los cobros, que no tenga un precio la vista del gobernador; que actúen con ecuanimidad los oídos del juez con los más pobres y los ricos; que sus ayudantes en la oficina imperial no reciban soborno alguno de los litigantes; que siempre está alerta la diligencia del gobernador, para que ninguno de este tipo de hombres tome nada de un litigante. Y si ellos creen que deben percibir algo de las causas civiles, acudirá la censura en armas para cortar las cabezas y los cuellos de los indignos, pues se ha dado a los extorsionados la facultad de que los gobernadores provinciales instruyan los oportunos expedientes. No obstante, si estos no hicieran caso de estas reclamaciones, damos voz a todos ante los comites provinciales o los prefectos del pretorio, para que, puestos en conocimiento de lo acaecido, hagamos aplicar los suplicios que correspondan por estos latrocinios ${ }^{53}$.

El edicto confirma lo que ya se ha podido ver en las leyes antes analizadas: era normal que los gobernadores no atendieran las reclamaciones, quizás por desinterés, pero, más bien, porque estaban implicados en muchos casos de prevaricación y cohecho. Para ello, el emperador recordaba que este tipo de delitos estaba castigado con la muerte (que sólo era aplicada circunstancialmente), $\mathrm{y}$, además, otorgaba a cualquier ciudadano, fuera el afectado o no, a denunciar estos comportamientos ante los cargos que asumían la inspección pública (a saber, en defecto de los gobernadores, los comites y prefectos del pretorio). El lenguaje empleado en el edicto era enfático, y buscaba producir una impresión indeleble en sus receptores ${ }^{54}$. De este modo, trataba de disuadir a los posibles culpables de prevaricación de continuar incurriendo en sus prácticas como de animar a la presentación de quejas. No obstante, en previsión de que la ley se prestara a empleos abusivos, otro probable fragmento del mismo texto advertía que se indagaría si las quejas eran veraces y no habían sido promovidas por clientes de potentados locales que trataban de apartar de sus funciones a jueces honestos 55 .

Una vez que los hijos de Constantino le sucedieran en el poder, el número de referencias legislativas a la queja administrativa se reduce notablemente, pues sólo hay cinco casos conocidos ${ }^{56}$. No se puede afirmar que los problemas advertidos por Constantino no perduraran con sus herederos. Las circunstancias del Imperio eran igualmente graves, pues al conflicto civil que enfrentó a Constantino II con su hermano Constante (337-340) le siguieron las usurpaciones de Magnencio, Vetranión y Silvano en Occidente (respectivamente entre 350-353, 350 y 355), entretanto que la amenaza bárbara se había incluso agravado en las fronteras renana y danubiana ${ }^{57}$. Más bien lo que había cambiado era el interés, por parte de los nuevos Augustos, en atender este tipo de cuestiones. Constantino insistía en sus textos legislativos en que tenía que ser puesto al corriente por carta de todos los casos de querimonia que se produjeran para resolverlos él mismo. Constancio II y Constante, sin embargo, no fueron tan receptivos hacia las reclamaciones administrativas o, al menos, no consta que lo fueran. Con todo, se debe observar que la atención de cada uno de ellos en relación con estas cuestiones fue distinta.

53 CTh. I, 16, 7.

54 Kelly 2004, 213-214; Marcone 2006, 122; Reitzenstein-Ronning 2015, 270-271.

55 CTh. I, 16, 6 (CI. I, 40, 3). Cf. Dupont 1973, 332; Slootjes 2003, 323, n. 20.
56 CTh. XII, 1, 27 (339); VII, 9, 1 (340); XI, 34, 2 (355); II, 1, 3 (357); VIII, 4, 6 (358).

57 Véase sobre estos acontecimientos: Piganiol 1972², 94-105. 
Constante atendió en 340 las quejas que le habían llegado acerca de los abusos perpetrados por sus soldados en Italia. La ley fue recibida en Capua, debió de ser cursada en el contexto de los movimientos de tropas en la guerra civil contra Constantino II $^{58}$. En virtud de la misma, Constante recordaba que los ciudadanos estaban obligados a albergar a soldados, pero no podían ser forzados mediante violencia a entregarles aceite, leña o cualquier otra cosa necesaria para su manutención. De darse esta situación, los provinciales podían presentar una querimonia al prepósito de la legión. El objeto de la medida era eminentemente práctico: trataba de fomentar que los ciudadanos que prestaban hospedaje a los soldados actuaran con generosidad, garantizando que no se les exigiría nada en contra su voluntad o por encima de sus posibilidades económicas y las de sus patronos ${ }^{59}$.

En el caso de Constancio II, su preocupación por atender las reclamaciones administrativas no fue tanta como la que mostró su padre Constantino. No obstante, en el año 355, envió al prefecto del pretorio de Italia, Volusiano, una instrucción en la que prescribía que quienes hicieran apelación de una sentencia ante el prefecto de la Ciudad o el gobernador de la provincia, y no fuera atendida su petición, tenían derecho a pedir la protección (praesidium) del emperador si declaraban y demostraban que habían sido coaccionados por el juez. No obstante, Constancio hacía una excepción: que la sentencia hubiera sido pronunciada por un vicario diocesano, caso en el que no aceptaría la reclamación ${ }^{60}$. Esta ley demuestra que la eficacia de los mecanismos legales para expresar la protesta era cuestionable. Como se ha podido comprobar, el miedo limitaba la capacidad legal de los ciudadanos de dirigir una reclamación al prefecto del pretorio.

Sin embargo, Constancio II continuó ofreciendo amparo legal a quien quisiera dirigirle reclamaciones contra oficiales imperiales. Ni siquiera estaban a salvo de ellas los agentes in rebus, los inspectores imperiales encargados de supervisar la actuación de los gobernadores provinciales. De hecho, atendiendo a Libanio, aunque este cuerpo de oficiales debía velar por el orden burocrático, con frecuencia amparaban prácticas abusivas e incluso incurrían en ellas ${ }^{61}$. Una ley de 357 advertía de que los cargos públicos, fueran magistrados u oficiales imperiales, serían encausados, incluso bajo el tormento del potro, si se encontraban indicios de que hubieran incurrido en delito. Entre las situaciones que podían dar lugar a su procesamiento estaban los abusos en el ejercicio de sus funciones, pero también las agresiones sexuales. No obstante, la ley preveía que, si las acusaciones resultaban ser falsas, el denunciante debería afrontar el doble de la pena que correspondiera al encausado $^{62}$. La norma, al mismo tiempo, crea el marco normativo necesario para evitar la impunidad de los cargos públicos y administrativos, pero también disuade a los denunciantes. Sobre todo, porque la justicia romana carecía de medios probatorios, siendo el examen de las declaraciones, tanto de las partes como de los testigos, la principal procedimiento del que se servían los jueces para esclarecer un caso.

Muy posterior en el tiempo es una ley de Constancio II, dirigida en 358 al Prefecto del Pretorio de Italia, Tauro, por la que el emperador concedía a los primipilares, jefes de legión que se encargaban periódicamente de gestionar las provisiones de las tropas, que los duces no percibieran más abastos de los que habían recibido en época de Constantino ${ }^{63}$. Al parecer, los duces (encargados, en

\footnotetext{
58 Amiano Marcelino (XXII, 4, 6-7) comenta que durante el principado de Constancio II se había relajado la disciplina militar, siendo frecuente que los soldados robasen a sus conciudadanos, en lugar de atacar a los bárbaros. Aunque se trataba de una nueva expresión literaria del motivo de la insolentia militum, la existencia de una regulación que trataba de controlar
}

los abusos cometidos por soldados refleja que el problema era real.

59 CTh. VII, 9, 1.

60 CTh. XI, 34, 2.

61 Liban., Or. XVIII, 140. Cf. Di Paola 2005, 83-84.

62 CTh. II, 1, 3.

63 CTh. VIII, 4, 6. 
este caso, de las tropas establecidas en las fronteras renana y danubiana) estaban exigiendo contribuciones mayores de las que hasta entonces tenían estipuladas. Además, requerían, en lugar de suministros, aportaciones en moneda. Estas demandas injustificadas habían hecho que los primipilares acabaran presentando ante el emperador una reclamación. La ley debe de hacer frente a los no extraños casos de malversación de asignaciones a las tropas de frontera. Para impedirlo, la ley establece que los gobernadores de provincia elaboraran registros públicos de las contribuciones que se hacían a las tropas. Los magistrados, además de validar la contabilidad de los suministros, tenían también que velar porque estos fueran entregados en especie, y no en moneda. Obviamente, la provisión trataba de evitar el mal uso de fondos públicos, pues prohibía que se entregaran monedas en concepto de abastos. Nuevamente, la figura de la querimonia era empleada para tratar de poner fin a conductas abusivas por parte de cargos públicos (civiles o militares), que respondían a prácticas irregulares.

Los ciudadanos romanos tenían el derecho e incluso la obligación de emplear la querimonia para denunciar casos de malos usos administrativos por parte de magistrados y oficiales. Cuestión aparte es si tales medios eran eficaces. Constantino ordenó que todas las reclamaciones llegaran a su directo conocimiento. Sus hijos no mostraron tanto interés en obtener información directa sobre estas cuestiones. Lo cierto es que apenas existe información documental sobre la tramitación de las quejas administrativas. Todavía encontramos menos referencias en la literatura. Pero siempre hay excepciones. En concreto, Libanio y Amiano Marcelino recogen la noticia de un posible caso de querimonia que fue instruido en la prefectura de las Galias en 358, cuando Juliano era allí césar de Constancio II. Libanio recuerda que un ciudadano había denunciado a un gobernador por pedir sobornos $^{64}$. Gracias a la obra de Amiano, este personaje puede ser identificado con Numerio, gobernador en la Galia Narbonense ${ }^{65}$. La reclamación fue atendida por Florencio, el Prefecto del Pretorio, a quien el propio Libanio tachaba de corrupto y acusaba de haber participado en el cohecho. Libanio se refiere al procedimiento como un juicio (pues emplea en su narración el verbo dikázo) y otro tanto hace Amiano. Parece que el juicio contra Numerio debió de comenzar a resultas de una querimonia, en consideración de las características de los cargos. En efecto, el prefecto empezó a hostigar al denunciante, pero se produjeron una serie de protestas populares que pedían que el césar examinase el caso. Al principio, Juliano trató de negarse a instruir el procedimiento, asegurando que no estaba entre sus competencias hacerlo. Quizás adoptó esta actitud haciendo una interpretación forzada del edicto constantiniano de 327 que disponía que los prefectos atendieran y reunieran la información pertinente a este tipo de denuncias ${ }^{66}$. Al final, debido a la presión general, acabó por acoger la denuncia, pero absolvió a los implicados por falta de pruebas, aunque todos los indicios apuntaban a que eran culpables. Amiano recoge algunos de los pormenores del proceso: un abogado, Delfidio, llegó a decir a Juliano: ¿(...) quién podrá ser culpable (...) si basta con negar los cargos? A lo que Juliano respondió: ¿Y quién podrá ser inocente, si basta con acusarle? ${ }^{67}$. Ante este diálogo judicial cabe preguntarse si los posibles testigos tuvieron valor para personarse en el tribunal y declarar contra el gobernador y el prefecto. La absolución de los encausados fue percibida por Libanio como una evidencia de prevaricación por parte de Juliano, aunque Amiano se refería a ella para mostrar la ecuanimidad del césar. Libanio, por su parte, no oculta la razón de la protección que le brindaba Juliano a Florencio: ambos tenían entonces buenas relaciones ${ }^{68}$. A lo cual hay que

64 Liban., Or., XVIII, 84.

${ }_{65}$ Amm. Marc., XVIII, 1, 4.

${ }^{67}$ Amm. Marc., XVIII, 1, 4.

${ }^{66}$ CTh. I, 5, 2.

68 Liban., Or. XVIII, 85. 
añadir que a Juliano le convenía mantenerlas: Florencio había sido nombrado por Constancio II y era leal sólo al Augusto. Había apoyado a Juliano cuando preparaba la compaña contra los bárbaros en 356, pero no había respaldado la decisión del césar de no imponer impuestos extraordinarios en Galia, razón por la que comenzaron a distanciarse ${ }^{69}$. Según Amiano, Florencio no se sentía respaldado por Juliano. Entonces, comenzó a enviar informes negativos sobre Juliano a Constan$\mathrm{cio}^{70}$. Finalmente, Florencio, cuando las tropas hicieron Augusto a Juliano, huyó de las Galias para estar al lado de Constancio ${ }^{71}$.

Este episodio muestra las limitaciones con las que se encontraban los ciudadanos en el momento de hacer una reclamación administrativa. De acuerdo con las leyes imperiales, podían formularla, pero las posibilidades de que esta tuviera éxito estaban a merced de la voluntad de los príncipes. Los gobernadores tendían a desentenderse de ellas o incluso trataban de obstaculizarlas. En el caso del prefecto Florencio, parece que recurrió incluso a la amenaza y a la obstrucción de la justicia. Estos gestos debían de ser frecuentes. Además, no siempre prosperaban. El césar Juliano, en concreto, se debió de negar a atender la queja por sus buenas relaciones con el prefecto. Pero tampoco consta que emprendiera acciones contra el promotor de la queja, estando facultado para ello. Quizás sólo la presión pública lo impidió. En este sentido, es probable que las quejas de carácter colectivo tuvieran más peso que las individuales. De hecho, Dupont y Slootjes han planteado que su instrucción partía de los concilios provinciales, curias y colegios y que muy raramente se debía a iniciativas individuales ${ }^{72}$. Y, en efecto, las concesiones de Constantino a los porqueros itálicos de 324 y a los provinciales africanos de 335 parece que eran respuestas a requerimientos colecti$\operatorname{vos}^{73}$. Pero nada impedía la posibilidad de que un ciudadano, a título particular, iniciara estos procedimientos. En concreto, el edicto de 331 estipulaba que los afectados por las exigencias de dinero por parte de cargos públicos podrán dirigirse a su gobernador para que este abriera los expedientes necesarios ${ }^{74}$. En este caso, se debe referir a causas particulares, para cada una de ellas se iniciaba un proceso distinto.

\section{Conclusiones}

La introducción en el Imperio de un sistema burocrático al servicio de los príncipes, cuyo fin esencial era obtener un mejor control de la administración en Roma (donde ya no residían los Augustos) y las provincias, que, atomizadas y multiplicadas, no podían ser gobernadas desde una corte casi itinerante. Los magistrados y oficiales imperiales, civiles y militares, apoyados en un sistema ordenado, pero falto de medios de inspección eficientes, tendían a aprovecharse del mismo. La introducción de la queja administrativa o querimonia, en el año 313, trataba de proporcionar a los ciudadanos un recurso expeditivo para poder defenderse de los abusos de gobernadores de provincia, jueces, oficiales subalternos e incluso de los supervisores de la burocracia, como eran los agentes in rebus.

Constantino y, al menos, Constante y Constancio II, ofrecieron y facilitaron a los ciudadanos su empleo para evitar males mayores como podían ser revueltas o, simplemente, la extensión del malestar en unos tiempos bastante difíciles, con una presión fiscal muy elevada y un índice de corrupción todavía mayor, a las que se sumaba la inseguridad de unas fronteras cuyas tropas apenas

${ }^{69}$ Amm. Marc., XVI, 12, 14; XVII, 4, 2.

70 Amm. Marc., XX, 4, 2.

${ }^{71}$ Amm. Marc., XX, 8, 20.

72 Dupont 1973, 331; Slootjes 2003, 322-324.

73 CTh. XIV, 4, 2; CTh. XII, 1, 21.

${ }^{74}$ CTh. I, 16, 7. 
podían controlar las incursiones bárbaras. Por otra parte, este medio de protesta era de gran utilidad política para los emperadores, pues gracias a ellas podían informarse acerca de la conducta de los gobernadores, de sus subalternos e incluso de sus inspectores. No obstante, su eficacia era limitada. Como se ha indicado, los magistrados y oficiales ejercían una presión fortísima sobre los ciudadanos, tal que muchas veces era disuasoria. Además, sólo prosperaban si los príncipes estaban dispuestos a atenderlas. Esto exigía que, para formular una querimonia, quienes la solicitaban debían organizarse, y acaso contar con apoyos fuera de los círculos locales. Con todo, el procedimiento ofrecía la posibilidad regulada de ejercer el derecho de protestar con aparentes garantías legales a quienes, a falta de un buen patrono, se encontraban indefensos frente a cargos públicos inoperantes cuando no manifiestamente prevaricadores.

\section{BiBLIOGRAFÍA}

Aparicio Pérez, A., 2012, La hacienda pública en el Bajo Imperio Romano (años 284 a 476 d.C.), Madrid: Dykinson.

Cecconi, G.A., 2005, «Conscience de la crise, groupements de pression, idéologie du beneficium: l'État impérial tardif pouvait-il se réformer?», AnTard 13, 281-304.

Corcoran, S., 2000², The Empire of the Tetrarchs. Imperial Pronouncements and Government, AD 284-324, Oxford: Clarendon Press.

Delmaire, R., 1995, Les institutions du Bas-Empire romain de Constantin à Justinien. I. Les institutions civiles palatines, Paris: Le Cerf.

De Martino, F., 1975, Storia della costituzione romana IV.2, Napoli: Jovene.

Dillon, J.N., 2012, The Justice of Constantine: Law, Communication, and Control, Ann Arbor: The University of Michigan Press.

Di Paola, L., 2005, Per una storia degli «occhi del re»: i servizi ispettivi nella Tarda Antichità, Messina: Università degli Studi di Messina.

Dupont, Cl., 1973, «Sujets et citoyens sous le Bas-Empire romain de 312 à 565 après Jésus-Christ», RIDA 20, 325-339.

Forcellini, E., 1940, Lexikon totius latinitatis III, Patauii: Apud Seminarium.

Gaudemet, J., 1949, "Constantin, restaurateur de l'ordre», en: Studi in onore di Siro Solazzi nel cinquentesimo anniversario del suo insegnamento (1899-1948), Napoli: Jovene.

—, 1951, "Constantin et les curies municipales», Iura 2, 44-75.

—, 1966, Institutions de l'Antiquité, Paris: Sirey.

—, 1979, «Mutations politiques et géographie administrative: l'Empire romain de Dioclétien (284) à la fin du Ve. siècle», en: La géographie administrative et politique d'Alexandre à Mahomet. Actes du Colloque de Strasbourg. 14-16 Juin 1979, Leiden: Brill, 255-272 (=Les gouvernants à Rome. Essais de Droit public romain, Napoli: Jovene, 165-182).

—, 1981, "Constitutions constantiniennes relatives à l'appel», ZSS (RA) 98, 47-76.

Hayashi, N., 1996, "L'appello e altri mezzi processuali sotto l'imperatore Costantino I», en Atti dell'Accademia Romanistica Costantiniana 11, Perugia: Università degli Studi di Perugia, 69-78.

Heumann, H.G., Seckel, E., 1907, Handlexikon zu den Quellen des römischen Rechts, Jena: Gustav Fischer.

Jones, A.H.M., 1964, The Later Roman Empire, 284-604. A Social, Economic and Administrative Survey IIII, Oxford: William Blackwell.

Kelly, Chr., 2004, Ruling the Later Roman Empire, Cambridge: Harvard University Press.

Kolb, A., 2000, Transport und Nachrichtentransfer im römischen Reich, Berlin: Akademie Verlag.

Laquerriére-Lacroix, A., 2014, «La portée normative des rescripta ad consultationis emissa sous Constantin», Fundamina 20.2, 527-535. 
Liebs, D., 1995, «Die pseudopaulinischen Sentenzen. Versuch einer neuen Palingenesie», ZSS (RA) 112, 151-170.

—, 1996, «Die pseudopaulinischen Sentenzen II. Versuch einer neuen Palingenesie», ZSS (RA) 113, 132242.

MacMullen, R., 1976, Roman Government's Response to Crisis, A. D. 235-337, New Haven: Yale University Press.

—, 1988, Corruption and the Decline of Rome, New York: Yale University Press.

Maraval, P., 2011, Constantin le Grand: empereur romain, empereur chrétien (306-337), Paris: Tallandier.

Marcone, A., 2006, «La corruzione nella tarda antichità», RSA 36, 115-127.

Millar, F., 1977, The Emperor in the Roman World (31 BC-AD 337), London: Duckworth.

—, 2004, Rome, the Greek World and the East: Government, Society and Culture in the Roman Empire, Chapel Hill and London: The University of North Carolina Press.

Moreno Resano, E., 2014, "La divinidad y el culto imperiales en la legislación de los siglos IV y v d.C.», $A R y S, 13,341-366$.

—, 2015, "Ad nostram scientiam referatur: la supervisión administrativa imperial de la aplicación de las leyes durante la dinastía constantiniana», Gerión 33, 191-209.

Pergami, F., 2007, Amministrazione della giustizia e interventi imperiali nel sistema processuale della Tarda Antichità, Milano: Giuffrè.

Piganiol, A., 1972², L’Empire chrétien (325-395), Paris: Presses Universitaires de France.

Porena, P., 2012, «I dignatari di Costantino: dinamiche di selezione e di ascesa durante la crisi del sistema tetrarchico», en G. Bonamente, N. Lenski y R. Lizzi Testa (eds.), Costantino prima e dopo Costantino, Bari: Edipuglia, 293-320.

Reitzestein-Ronning, Chr., 2015, «Performing Justice: The Penal Code of Constantine the Great», en J. Wienand (ed.), Contested Monarchy: Integrating the Roman Empire in the Fourth Century AD, Oxford: Oxford University Press, 265-288.

Schuller, W., 1975, «Grenzen des Spätrömischen Staates: Staatspolizei und Korruption», ZPE 16.1, 1-21.

Slootjes, D., 2003, «Between Criticism and Praise: Provincials' Image of the Governor in the Later Roman Empire», en L. De Blois, P. Erdkamp, O. Hekster, G. De Kleijn, St. Mols (eds.), The Representation and Perception of Roman Imperial Power. Proceedings of the Third Workshop of the International Network Impact of Empire (Roman Empire, c. 200 B.C.-A.D. 476), Netherlands Institute in Rome, March 20-23, 2002, Amsterdam: J.C. Gieben, 318-326.

—, 2006, The Governor and his Subjects in Later Roman Empire, Leiden: Brill.

Teall, J.L., 1967, "The Age of Constantine: Change and Continuity in Administration and Economy», DOP 21, 11-36.

Van Dam, R., 2011, Remembering Constantine at the Milvian Bridge, Cambridge: Cambridge University Press.

Veyne, P., 1981, «Clientèle et corruption au service de l'état: la vénalité des offices dans le Bas-Empire romain", Annales ESC, 339-360.

Vogler, Ch., 1979, Constance II et l'administration impériale, Strasbourg: Groupe de Recherche d'Histoire Romaine de l'Université des Sciences Humaines de Strasbourg. 